IOS Press

\title{
Monitoring Drosophila suzukii in Switzerland in $2012^{1}$
}

\author{
Catherine A. Baroffio ${ }^{\mathrm{a}, *}$, Pauline Richoz ${ }^{\mathrm{a}}$, Serge Fischer ${ }^{\mathrm{b}}$, Stefan Kuske ${ }^{\mathrm{c}}$, Christian Linder ${ }^{\mathrm{b}}$ \\ and Patrik Kehrli ${ }^{\mathrm{b}}$ \\ ${ }^{a}$ Agroscope-ACW, Research Center Conthey, Conthey, Switzerland \\ ${ }^{\mathrm{b}}$ Agroscope-ACW, Changins, Nyon, Switzerland \\ ${ }^{\mathrm{c}}$ Agroscope-ACW, Wädenswil, Schloss, Wädenswil, Switzerland
}

Received 21 October 2013; accepted 16 December 2013

\begin{abstract}
.
BACKGROUND: Drosophila suzukii is a highly polyphagous vinegar fly native to Asia, which invaded Switzerland in 2011. The pest was found in all regions of the country, from low altitudes to the timberline. Due to its fast reproduction rate and the infestation of fruits shortly before harvest $D$. suzukii is difficult to control.

OBJECTIVE: Our main objective was to establish an efficient monitoring campaign all over Switzerland.

RESULTS: In 2012, a total of 60,000 D. suzukii were captured in 200 monitoring traps, whereupon it represented between 25 and $75 \%$ of all vinegar flies trapped. The range of host plants is very broad, not only affecting crops, but also wild fruits. In 2012 most individuals were captured close to or within cultivated raspberry, blackberry and grapevine as well as in wild shrubs such as elderberry. It is likely that as a result of a consequent application of the recommended sanitation measures, only very few cases of economic damage were reported by the producers in 2012 .

CONCLUSIONS: Monitoring traps can reliably detect the occurrence of the pest in a region. The trap must be very selective to small insects (diameter of $3 \mathrm{~mm}$ ) to avoid other beneficial insects such as Lepidoptera and Hymenoptera being caught. In case of local presence, setting up a dense net of mass-traps around the crop or between a hedge and the crop should guarantee capture of most vinegar flies before they attack ripe fruits. In close collaboration with national and international partners, Agroscope will try to identify pragmatic and sustainable crop protection measures against $D$. suzukii.
\end{abstract}

Keywords: Drosophila suzukii, berry, monitoring, trap selectivity

\section{Introduction}

The Spotted wing Drosophila, Drosophila suzukii [1] is native to Southeast Asia. Since its introduction in America and Europe, it has caused extensive damage to fruit crops, particularly cherries and berries [2, 3]. Drosophila suzukii was first discovered in Spain at the end of 2008 and thereafter it was found in 2009 in Italy, the South of France and Corsica in 2010 as well as in Switzerland in 2011 [4]. Since then it also invaded Germany, Austria, Belgium and the UK.

The Spotted wing Drosophila belongs to the family Drosophilidae, has a length of $2-3 \mathrm{~mm}$, red eyes and a yellowish brown body. The male can be identified easily thanks to a distinct dark spot near the tip of each wing, which is lacking in native Drosophila species. Like the common vinegar fly species, the wings of females are unspotted. However, they have a long, sharp, serrated ovipositor, which is much more pronounced than in native species. This toothed ovipositor distinguishes $D$. suzukii females from native species and allows them to pierce the fruit skin. Whereas common vinegar flies attack damaged, overripe or rotting fruits, D. suzukii lays its eggs in healthy, intact, ripe fruits.

\footnotetext{
${ }^{1}$ Paper presented at 2nd International Strawberry Congress, Hoogstraten, Belgium, Sept. 4-6, 2013.

*Corresponding author: Catherine A. Baroffio, Agroscope-ACW, research Center Conthey, rte des vergers 18, 1964 Conthey, Switzerland. Tel.: +4127345 35 18; E-mail: Catherine.baroffio@agroscope.admin.ch.
} 


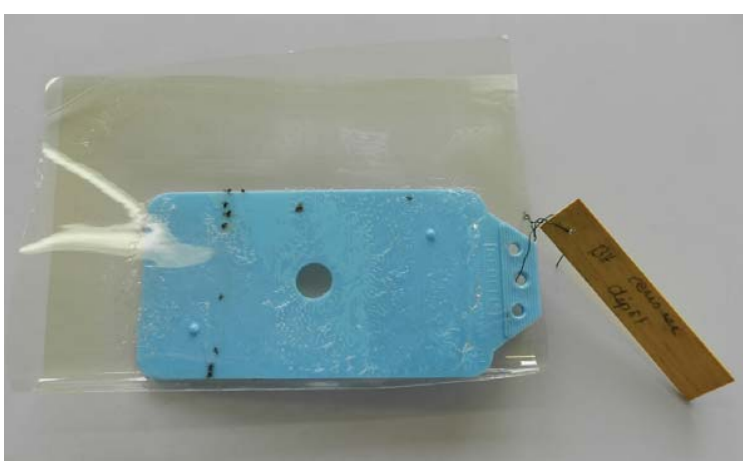

Fig. 1. Blue sticky trap ready to be sent.

The larvae grow up to $6 \mathrm{~mm}$ long and feed on the pulp of the fruits, which frequently leads to the sagging of the subepidermal tissues of infested fruit (internal breakdown). Pierced and damaged fruits may consequently also be colonized by fungi, bacteria and common vinegar flies. Another worrying feature of the novel pest is its ability to build up enormous populations over the summer. A female is able to lay more than 400 eggs during her life cycle over several months. In addition, the life cycle development from egg to adult takes only ten days in the mid of summer, which enables the species to have more than 10 generations over the season. Although D. suzukii shows a general preference for red and dark fruits [5], it nevertheless attacks nearly all soft fruits as well as other fruits, such as cherries, peaches, plums, apricots and grapes, figs, kiwi and persimmon. It is abundantly found on cultivated as well as wild fruits $[6,7]$. Due to the exponential growth of its populations over the year, late berry cultures are at particular risk, e.g. blackberries (brambles), blueberries and autumn fruiting raspberries.

In 2011, Agroscope launched its first monitoring survey by placing vinegar traps in crops at potential risk. At the end of the year, the presence of D. suzukii in Switzerland was confirmed [8]. In 2012, the monitoring network was intensified in order to follow population dynamics over time, space and crops at national level. The selectivity of different kind of commercial traps was also compared to our own model (Agroscope trap).

\section{Materials and methods}

\subsection{Monitoring 2012}

The monitoring was conducted in all Swiss cantons all over the country. The network consisted of about 200 traps distributed according to the importance of fruit growing areas (between 2 to 15 traps/canton). The traps consisted of a polystyrene box of $1300 \mathrm{ml}$ (Agroscope trap) containing $200 \mathrm{ml}$ of attractive liquid. The liquid was composed of a mixture of equal parts of apple cider vinegar and water, a small amount of red wine (about 5\%) in order to increase the mixture's attractiveness, as well as a drop of detergent to reduce the surface tension of the liquid. A blue sticky trap (Rebell blu ${ }^{\circledR}$ ) was placed in the middle of the trap to facilitate the identification and shipment of captured insects. Between May and July 2012, the monitoring traps were placed in cherry and strawberry crops, followed by raspberry, blackberry, blueberry crops and in autumn they were finally set-up in vineyards. The traps were checked on a weekly basis and the blue sticky traps were sent to Agroscope Conthey for identification of captured vinegar flies and other insect species (Fig. 1).

\subsection{Selectivity of monitoring traps}

The three commercial traps "Droso-Trap", "McPhail" and "SentomoP" were compared to the Agroscope trap (Table 1). The trial first took place in three cherry orchards in June 2012 and in July the traps were placed in two raspberry crops [9]. The four trap models were placed in a line in a distance of 2 meters between traps. All traps 
Table 1

Description of the 4 traps used in the trial in 2012

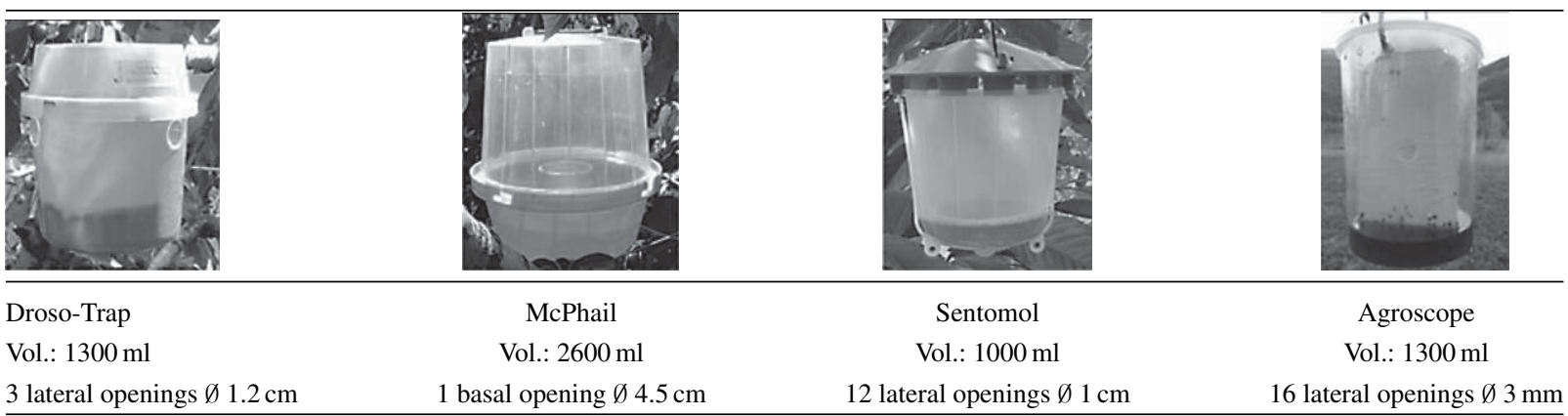

Table 2

Total catches in 2012

\begin{tabular}{lccr}
\hline & Total catches & Trap number & Mean captures/trap \\
\hline April & 0 & 120 & 0 \\
May & 3 & 168 & 0.01 \\
June & 32 & 184 & 0.13 \\
July & 407 & 196 & 0.83 \\
August & 2396 & 455 & 4.40 \\
September & 8451 & 495 & 14.62 \\
October & 33673 & 303 & 40.36 \\
November & 11840 & 46 & 116.48 \\
December & 51 & 20 & 0.46 \\
TOTAL & 56853 & 1867 & \\
\hline
\end{tabular}

were filled with $250 \mathrm{ml}$ attractive liquid composed of $50 \%$ water, $40 \%$ apple vinegar, $10 \%$ red wine and a drop of liquid detergent. The traps were checked each week and captured insects were subsequently identified. Captured insects were assigned in the following categories: a) D. suzukii, b) Drosophila sp., c) Muscidae, d) Aniposodidae, e) Scatopsidae, f) Lepidoptera, g) Hymenoptera and h) others.

\section{Results and discussion}

\subsection{Monitoring 2012}

In less than two years, $D$. suzukii has established itself all over the country. In 2012, more than 60,000 individuals were captured. The recordings of the population development including crops affected, progression and location of spread were published on the open access website www.drosophilasuzukii.agroscope.ch. The first discovery was reported in a cherry orchard of the canton of Ticino (southern part) in the month of May 2012. Drosophila suzukii was registered from July onwards over the whole of Switzerland. The insect was captured from the plain to the subalpine zone of the Jura and the Alps. Although it is risky to compare the results from different regions, Ticino seems to host the largest $D$. suzukii population. The number of individuals captured increased over the season as a result of the buildup of pest populations over the summer (Table 2, Fig. 2). The peak of insect activity was thus recorded between mid-September and late October. This peak is in correspondence with the observations in neighboring countries [10].

Overall, the number of $D$. suzukii catches was highest in late fruit crops such as raspberries, blackberries and blueberries and in the surrounding of vineyards (Fig. 3). Monitoring traps placed in hedges, including elderberry and Viburnum sp. also captured large numbers of D. suzukii. In these natural areas, monitoring was continued over the 


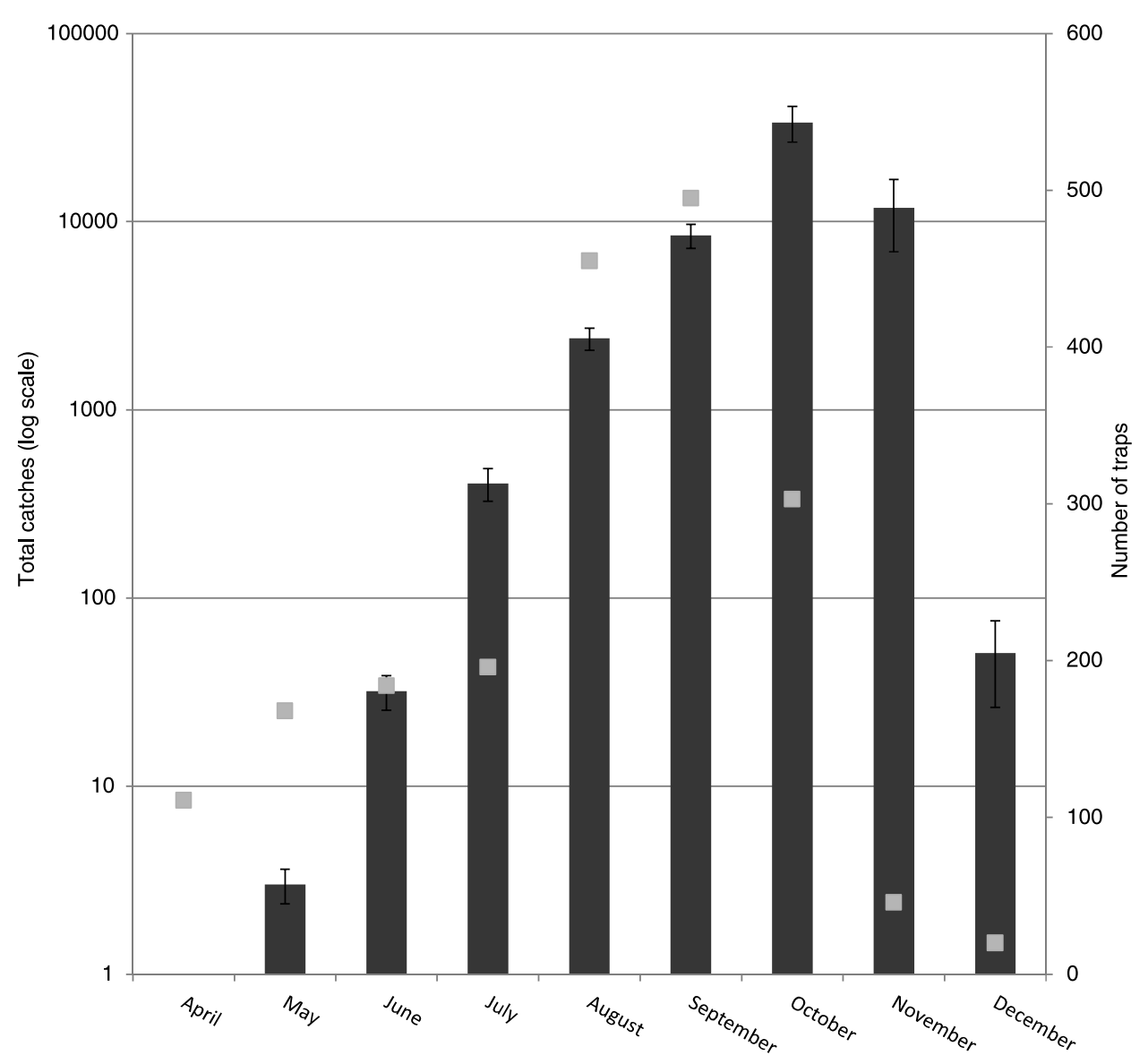

Fig. 2. Captures of D. suzukii between April and December 2012 on 200 traps. Left axis: Total catches (black bars, log scale) . Right axis: Number of traps (grey squares).

winter 2012-13. Catches fell sharply in the end of November stopping altogether in January (snow being present). Individual captures were once again recorded in February. It may be that a presence of snow cover helps the pest to overwinter. However, experiences made in areas with mild winters, such as for example southern France, show the D. suzukii can be captured throughout the winter (Claire Weyert, CTIFL, pers. Comm.).

\subsection{Selectivity of monitoring traps}

Unfortunately the spread of $D$. suzukii begun in this region of Valais after the trapping period and therefore not a single individual was captured in the four trap designs tested from June to July. In the traps set-up in the cherry orchards, $46 \%$ of the insects captured were native vinegar flies or other small Dipterans and $14 \%$ Scatopsidae. In traps located in raspberry, native vinegar flies and small Dipterans made up 40\% of the catch and Muscidae 30\%. Only the Agroscope trap with openings of $3 \mathrm{~mm}$ showed a high selectivity for vinegar and other small flies (Fig. 4). The openings of the commercialized trap models were of at least $1 \mathrm{~cm}$ and the "Droso-Trap, "McPhail" and "Sentomol" captured consequently a large number of Lepidopterans, and the latter two also many Hymenopterans. These results show that the first primary criterion for a selective monitoring trap is the diameter of the openings, which should not exceed $3 \mathrm{~mm}$. Following this observation, the selectivity of the "Droso-Trap" was enhanced by adding a fine mesh tulle over the openings. Overall, the ideal trap has an attractive lure, is of a dark colour and has a high number of small openings $[11,12]$. 


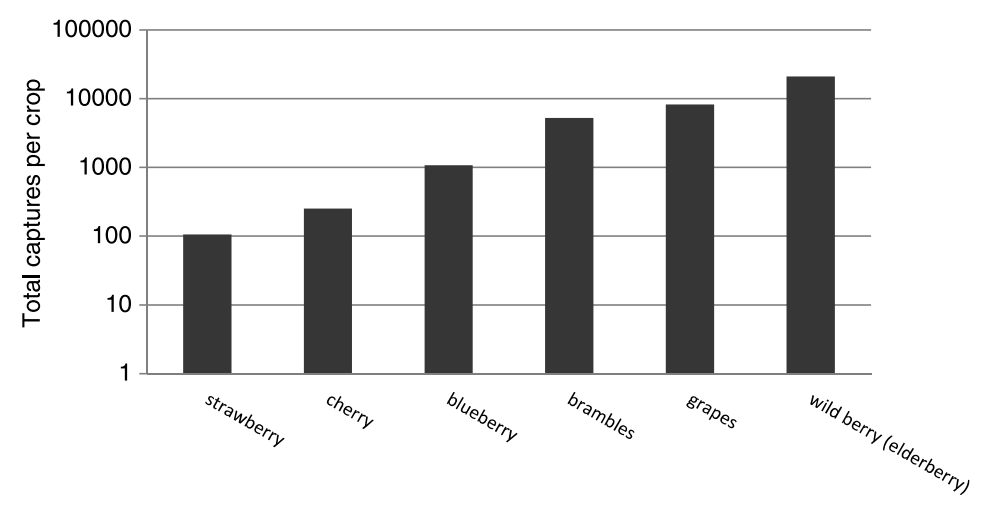

Fig. 3. Captures of D. suzukii between April and December 2012 on 200 traps pro crop (log scale).
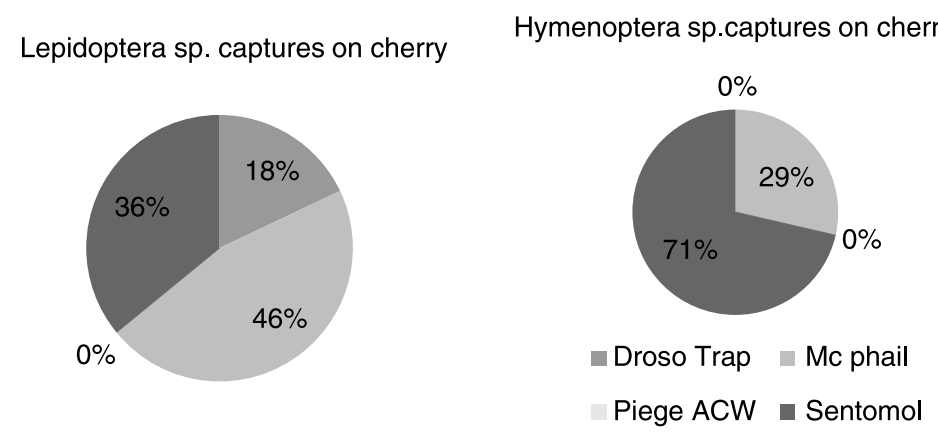

Lepidoptera sp. captures on raspberry

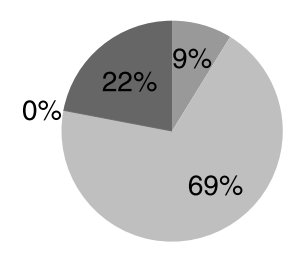

Piege ACW $\backsim$ Sentomo

Fig. 4. Repartition of the Lepidoptera and Hymenoptera catches in cherry and raspberry. Average of 3 traps.

\section{Conclusions}

The spotted wing Drosophila is now established all over Switzerland and late harvested fruits and berries are the most threatened. Overall, fruit growers, local advisors, phytosanitary services and the general public highly appreciated the publishing of the results of the monitoring network on our open-access website www.drosophilasuzukii.agroscope.ch. On this webpage they also found further information on the biology and control of this novel pest. In particular the phytosanitary measures, such as mass-trapping, early harvesting, the destruction of overripe, damaged and infested fruits and a short interval between harvest and consumption. Overall, the application of these phytosanitary measures against $D$. suzukii was very effective and almost none of the temporarily approved insecticides were applied by commercial growers. The only economic damages we are aware of in 2012 concerned a few strawberry and raspberry plantations in Valais, a single blackberry parcel in the area of Zurich, a raspberry plantation in Grison as well as a strawberry tunnel and some small vineyards in Ticino [13].

This study demonstrates that monitoring traps can reliably detect the presence of $D$. suzukii in a particular region, crop or plot. The trap must be selective to small insects (diameter of $3 \mathrm{~mm}$ ) to avoid other beneficial insects such as Lepidoptera and Hymenoptera being caught. Moreover, the surveillance of local populations by monitoring traps prompts fruit growers to observe the dynamics of the pest. This makes them aware of the potential risks and assists them to intervene in time.

\section{Acknowledgments}

Agroscope thanks all cantonal authorities, without their work we would never have been able to conduct this study. 


\section{References}

[1] Matsumura S. 6000 illustrated insects of Japan-empire (in Japanese). Tokyo: Tokoshoin; 1931, p. 1497.

[2] Goodhue RE, Bolda M, Farnsworth D, Williams JC, Zalom FG. Spotted wing drosophila infestation of California strawberries and raspberries: Economic analysis of potential revenue losses and control costs. Pest Management Science. 2011;67:1396-402.

[3] Calabria G, Maca J, Bachli G, Serra L, Pascual M. First records of the potential pest species Drosophila suzukii (Diptera: Drosophilidae) in Europe. Journal of Applied Entomology. 2012;136:139-47.

[4] Baroffio C, Richoz P, Arriagada B, Kuske S, Brand G, Fischer S, et al. Surveillance de Drosophila suzukii: Bilan de l'année 2012. Revue Suisse de Viticulture, Arboriculture, Horticulture. 2013;45(4):212-8.

[5] Cini A, Ioriatti C, Anfora G. A review of the invasion of Drosophila suzukii in Europe and a draft research agenda for integrated pest management. B Insectol. 2012;65(1):149-60.

[6] Baroffio C, Fischer S. Neue Bedrohung für Obstplantagen und Beerenpflanzen: Die Kirchessigfliege. UFA Revue. 2011;11:46-7.

[7] Kehrli P, Kuske S, Baroffio C, Fischer S, Linder C, Richoz P, et al. Kirschessigfliege, neu in der Schweiz. Schweiz Z Obst-Weinbau. 2013;149(4):8-13.

[8] Kehrli P, Höhn H, Baroffio C, Fischer S. La drosophile du cerisier, un nouveau ravageur dans nos cultures fruitières. Revue Suisse de Viticulture, Arboriculture, Horticulture. 2012;44(1):69-71.

[9] Salamanca B. Monitoring und Bekämpfungsstrategien gegen Drosophila suzukii in der Schweiz. 2012.

[10] Grassi A, Palmieri L, Giongo L. Drosophila (Sophophora) suzukii (Matsumura), new pest of soft fruits in Terntino (North-Italy) and in Europe. IOBC wprs Bulletin. 2012;70:121-8.

[11] Mitsui H, Takahashi HK, Kimura MT. Spatial distributions and clutch sizes of Drosophila species ovipositing on cherry fruits of different stages. Population Ecology. 2006;48:233-7.

[12] Edwards DL, Lee JC, Bruck DL, editors. Spotted wing drosophila monitoring: Building a better fly trap. 71st Annual Pacific Northwest Insect Management Conference; 2012; Portland.

[13] Linder C, Kehrli P, Kuske S, Baroffio C, Fischer S. La drosophile du cerisier, nouveau ravageur potentiel de nos vignobles. Revue Suisse de Viticulture, Arboriculture, Horticulture. 2013;45(1):59-62. 